\title{
29
}

\section{Galo de ouro e Memorial de Maria Moura: Rachel de QueIroz e AS CONTRADIÇÕES DO FEMININO - ENTRE A INDEPENDÊNCIA E A CONFORMAÇÃO}

\author{
Osmar Pereira Oliva ${ }^{1}$
}

RESUmo: Este trabalho pretende discutir os romances Galo de ouro e Memorial de Maria Moura, de Rachel de Queiroz, na perspectiva de gênero, ressaltando as representações do feminino, entre a independência e a conformação ao lar. Em sua maioria, as personagens femininas criadas pela autora cearense lutam por igualdade social, reivindicam liberdade de pensamento e poder de decisão nas relações afetivas e procuram resistir à subordinação ao masculino, ao mesmo tempo em que sentem a falta de uma companhia masculina, gerando a aparente contradição.

PALAVRAS-ChAVE: Feminino; Feminismo; Independência feminina; Conformação.

\section{GOLDEN COCK AND MARIA MOURA'S MEMORIAL: RACHEL DE QUEIROZ AND THE FEMALE CONTRADICTIONS - BETWEEN INDEPENDENCE AND CONFORMATION}

ABSTRACT: This work intends to discuss the novels Galo de ouro e Memorial de Maria Moura by Rachel de Queiroz, in the perspective of genre, emphasizing the feminine representations between independence and conformation. In its majority, the feminine characters created by the author from Ceará, fight for social equality, claim for freedom of thought and decision-making power in the affective relationships and aim to resist to the masculine subordination, at the same time that they miss a male company, generating an apparent contradiction.

KEYWORDS: Feminine; Feminism; Feminine independence; Conformation.

\section{Introdução}

Rachel de Queiroz nasceu em Fortaleza em 1910 e, com apenas vinte anos de idade, iniciou a sua carreira ficcional com o romance $O$ quinze (1930); nessa década, seguiram-se João Miguel (1932), Caminho de pedras (1937) e As três Marias (1939). Somente 36 anos depois a autora voltaria ao gênero romance, publicando Dôra, Doralina (1975), Galo de Ouro (1986) e Memorial de Maria Moura (1992). Nesse espaço de tempo, Rachel publicou também 05 livros de crônicas, 02 peças de teatro, 03 livros infantis e uma autobiografia. $^{2}$

\footnotetext{
${ }^{1}$ Mestre e doutor em Estudos Literários, pela Universidade Federal de Minas Gerais - UFMG. Professor efetivo do mestrado em Estudos Literários da Universidade Estadual de Montes Claros - Unimontes, onde desenvolve pesquisas sobre gênero e as linhas de força na literatura de autoria feminina. E-mail: osmar.oliva@unimontes.br 2 São eles, respectivamente: $A$ donzela e a Moura Torta (1948), Um alpendre, uma rede, um açude (1958), O caçador de tatu (1967), O homem e o tempo (1964-1976), As terras ásperas (1993); Lampião (1953), A beata
} 


\section{Criaçäo \&}

A jovem escritora tinha ideias avançadas para o seu tempo; além da consciência política, das leituras socialistas e das participações como cronista nos jornais $O$ Ceará, Diário de Notícias, O Cruzeiro e em O Jornal, era também filiada ao Partido Comunista brasileiro, mas com ele rompeu por discordar de certas ideologias que contrariavam as atividades da intelectual, da literata, discussão essa que aparece tão claramente no romance Caminho de Pedras. Por outro lado, em entrevista, Rachel de Queiroz afirmou que não era nem aceitava o rótulo de feminista. No entanto, suas personagens de grande relevo são as femininas, e agem, no plano ficcional, como poderiam agir as heroínas feministas da vida real. Em sua maioria, são mulheres que lutam por igualdade social, que reivindicam liberdade de pensamento e poder de decisão nas relações afetivas e que se afastam da subordinação ao masculino.

O fato de a autora cearense ter se envolvido com o Partido Comunista e, posteriormente, apoiado o Golpe Militar, com Humberto Castelo Branco, certamente contribuiu negativamente para a recepção crítica da sua obra, pouco lida e discutida ainda hoje nas Universidades. Afirmação semelhante se pode fazer pelas duras críticas que Rachel direcionava às feministas de sua época: "Eu sempre tive horror das feministas; elas só me chamavam de machista. Eu acho o feminismo um movimento mal orientado. Por isso sempre tomei providências para não servir de estandarte para ele." (QUEIROZ, 1997, p. 26) Heloísa Buarque de Hollanda, no ensaio "O éthos Rachel", discute a escassez de fortuna crítica sobre essa escritora, e afirma que:

Menos do que omissão ou rejeição, o que a crítica brasileira tem mostrado, na realidade, é medo de Rachel de Queiroz. Medo de enfrentar sua conflituosa relação com os movimentos feministas ou mesmo com a literatura escrita por mulheres que começa a se impor a partir do modernismo. Medo de explicitar as possíveis causas do sucesso e do poder público inegáveis de uma mulher que, desde adolescente, transitou com espantosa autoridade e naturalidade pelos bastidores da cena literária do país. Medo, sobretudo, de enfrentar a trajetória particular de seu pensamento político. (HOLLANDA, 1997, p.104)

Para Heloísa Buarque de Hollanda, a aversão de Rachel de Queiroz pelo feminismo foi decorrente de dois aspectos primordiais: primeiro, porque, engajada no Partido Comunista, seus ideais se distinguiam e se distanciavam dos ideais feministas, identificados com a política getulista. Segundo, porque Rachel considerava que a maioria das escritoras de sua geração representava, literariamente, o velho, o estilo ainda romântico e adocicado. Não é por acaso que o seu romance de estreia tenha sido considerado por alguns críticos como livro de macho, por causa do estilo seco, sem sentimentalismos, sem nobreza moral,

Maria do Egito (1957); O menino mágico (1983), Cafute \& Pena-de-Prata (1986), Andira (1992); Tantos anos (1998). 


\section{Criaçãa \&}

sem grandeza. Eduardo de Assis Duarte (2005, p. 106) corrobora essa afirmação, no sentido de que Rachel de Queiroz seguiu a trilha das mulheres que se colocaram na vanguarda de sua época e ousaram penetrar nos espaços ocupados essencialmente por homens, como 0 mundo das letras, a redação do jornal, a célula partidária.

Assim também, na contracorrente da literatura permitida para as mulheres, proibida nos colégios de freiras, Rachel escreveu quatro romances com ideias socialistas e feministas e suas personagens femininas, na maioria, seguem a mesma tendência de sua criadora. Trata-se dos romances O quinze (1930), João Miguel (1932), Caminho de pedras (1937) e As três Marias (1939), os quais já foram discutidos por mim em outro artigo, intitulado "Rachel de Queiroz e o romance de 30 - ressonâncias do socialismo e do feminismo", publicado nos Cadernos Pagu, no 43, Campinas Jul/Dez. 2014³.

\section{A vida em marcha à ré}

Galo de ouro (1989) é o penúltimo romance escrito por Rachel de Queiroz e considerado o único urbano, no sentido de que sua história não tem como cenário o Nordeste brasileiro, e sim o Rio de Janeiro, ainda que representando personagens populares, sem realce na sociedade carioca. É também um dos livros menos conhecidos dessa escritora, e ainda pouco discutido pela crítica acadêmica. Trata-se de uma narrativa que poderia ser considerada o resumo de Mariano, sua personagem central - para estabelecer uma analogia com o romance de Modesto Carone: Resumo de Ana (1998).

Um e outro são livros que contam os reveses de homens comuns, sem grandes aspirações, e que vão sofrendo perdas econômicas, afetivas, familiares e até mesmo físicas (aleijões) que deformam e debilitam Mariano (de Rachel de Queiroz) e Ciro (de Modesto Carone). Segundo o narrador construído pela autora cearense: "Homem novo (...) lá um dia arranja mulher e casa - e então começa a marcha à ré. Tudo que para ele sozinho chegava e dava de sobra vai ficando pouco e minguado." (QUEIROZ, 1989, p. 9). E, em Resumo de Ana: "Anita foi a companheira de Ciro até o fim da vida. Sua atitude de mulher disposta a encarar a pobreza sem desespero, traço herdado pelas seis filhas do casal, aplainou o caminho da vida em comum" (CARONE, 1998, p.88). Creio que um estudo comparado resultaria em um bom trabalho que, aqui, não desenvolveremos.

No começo do casamento, o jovem Mariano leva a moça para morar em seu quarto de solteiro; depois a mulher inicia planos para ter uma cozinha apenas sua, em um barraco com pedaço de quintal onde as crianças possam brincar. Assim que se mudam, obriga o marido a comprar louças e depois quer um guarda-louça para os pratos e as xícaras e um guarda-roupas, "e entre tantos desejos e tantas necessidades o homem vai se afogando.

\footnotetext{
${ }^{3}$ Disponível em: http://www.scielo.br/scielo.php?script=sci_arttext\&pid=\$0104-83332014000200385
} 


\section{Criacãa \&}

Primeiro levanta um empréstimo, depois começa a trabalhar de serão. E por mais que faça não há maneira do dinheiro chegar." (QUEIROZ, 1989, p. 10)

$O$ romance inicia com um resumo sobre a servilidade do homem aos caprichos de uma mulher. Por meio do discurso irônico, o narrador alerta ao leitor sobre as artimanhas de que se valem as mulheres para melhorarem cada vez mais o espaço doméstico, desde a aquisição da casa própria até a mobília, vestuário e outros pequenos adornos, sendo essas as primeiras necessidades básicas para uma família. Por outro lado, fica subentendido um princípio feminino de que um homem não deve prometer a uma mulher aquilo que ele não pode cumprir. Nazaré, quando Mariano a encontrou na praia, a caminho de sua casa, já revelava claramente suas ambições e julgamentos a respeito do lugar onde vivia, sem nenhum conforto. O rapaz soube logo de que era uma mocinha exigente e inconformada com a sua condição de pobreza. Ainda assim, prometeu-lhe uma vida melhor. Ela não se esqueceu das promessas feitas durante o namoro e o que fez, depois de casada e de ter filhos, foi simplesmente cobrar o que o marido já não podia oferecer. Mais uma vez o narrador não deixa o leitor no malogro, pois não escondeu as aspirações da personagem que nos apresenta ao longo da narrativa.

Se Nazaré é uma protagonista emblemática da insubordinação do feminino na galeria de personagens de Rachel de Queiroz, nesse mesmo romance Percília e dona Loura também não se enquadram no perfil de mulheres "domesticadas". Mariano vivia em um quarto de aluguel, dividido com um outro rapaz. Em sua ausência, recebia a jovem Percília, mulata clara, que não se preocupa com os julgamentos dos outros. O narrador nos informa que, desde que começara a frequentar o quarto de Mariano, este vinha pensando em casamento, mas Percília já havia se entregado a outro homem e ela mesma não ligava muito para o casamento. A moça engravida e vai morar com Mariano. Dona Loura também é uma mulher pouco convencional, pois desde os dezesseis anos vivia com seu Zé Galego, depois que passara duas noites na casa dele, durante um carnaval. Com a morte do seu companheiro e a separação do seu compadre Mariano, ela é quem propõe a ele que os dois juntem as duas famílias. Ainda que Rachel de Queiroz tivesse rejeitado o rótulo de escritora feminista, suas personagens encenam gestos ou ações de protestos contra a opressão e a discriminação da mulher. Dessa forma, o feminismo assume um sentindo muito mais amplo, como toda e qualquer atitude de reivindicação aos mínimos direitos da mulher e de inconformismo à submissão masculina.

Dona Loura e Percília aproximam-se, especularmente, pela crença espírita, motivo que renderia um interessante trabalho crítico, inédito na ficção de Rachel de Queiroz. No entanto, centralizaremos nossa análise em torno da personagem Nazaré, transgressora dos costumes tradicionais do matrimônio. Mariano encontrou Maria de Nazaré aos 17 anos, voltando de uma festa, de madrugada, acompanhada de um rapaz, duas velhas e outras moças. Vejamos como o narrador a descreve: 


\section{Criação \&}

Era alta, cheia de corpo, a cor do rosto fechada mas o cabelo liso. (...) Cortava o cabelo na altura dos ombros, pintava as unhas com esmalte cor-de-rosa e os lábios de vermelho vivo. Pó-de-arroz não Ihe empanava o moreno-escuro do rosto, e o vestido era tão curto que lhe descobria a curva dos joelhos. (QUEIROZ, 1989, p. 57).

Nazaré era uma moça bonita e conhecia a impressão sedutora que causava nos homens. Sua maquiagem e suas roupas são usadas com o propósito de despertar 0 interesse dos homens. Além disso, gostava de dançar, de namorar, de passear no Rio e chegar tarde da noite em casa. Nessa passagem, quando está voltando para casa, encontrase com Mariano, já viúvo de Percília, com quem tivera uma filha, acompanhado do seu amigo Salviano, que já fora namorado de Nazaré. Ela fala alto, para que o rapaz escute:

Prefiro uma boa morte a me casar com um sujeito da ilha, pra ir morar em rancho numa beira de praia dessas, cozinhar toda a minha vida numa trempe, me encher de filho e ver que estou me acabando na flor da vida, só de boba. Só porque não tive coragem de ir embora. (QUEIROZ, 1989, p. 60).

Esse encontro é significativo para que o leitor conheça as características físicas e as aspirações da jovem Nazaré. Ninguém poderá chegar ao final do romance desavisado do comportamento transgressor dessa mulher. Apesar de viver com a mãe na llha do Governador, em condições de pobreza, a jovem gosta mesmo é da cidade, do cinema, do movimento urbano. Enquanto espera melhor oportunidade para sair desse lugar de contrariedades, Nazaré namora Zezé, um típico malandro carioca, que passeia com ela pelo Rio e the oferece pequenos presentes: "o cabelo crespo repartido de lado, a pele morenoclara, as costeletas cortando a face quase pelo meio, o corpo franzino, o andar gingado, o peito de pombo, estufado, o olhar insolente, procurando briga..." (QUEIROZ, 1989, p. 80)

O narrador ainda informa que o malandro era sustentado por mulheres: gigolô e cafetão. Mariano era a esperança de mudança. Apresentava-se arrumado, com algum dinheiro; dava presentes a Nazaré e não era homem atrevido, como o outro. E namorava os dois ao mesmo tempo. Zezé sairá de cena, quando rouba um anel de rubi e dá de presente a Nazaré. Mariano, enciumado, denuncia-o à polícia. O malandro é perseguido até jogar-se ao mar e morrer afogado. O enamorado promete dar-lhe outro anel de igual valor, demonstrando a sua subserviência. Para se ver livre da mãe, que tentava controlar seus impulsos negativos, e não se entregar aos infortúnios de lavar roupas e engomar para os outros, mesmo de menor idade, Nazaré se propõe a ir viver com Mariano. A mãe dela se opõe, mas procura o viúvo, exigindo que ele se case com a sua filha. Acertada a situação, o narrador descreve o casamento: 


\section{Criaçãa \&}

Ela se vestiu de noiva, Mariano deu-lhe a seda, depois pagou o feitio: cetim brochê com cauda, sim cauda, arrastando pelo adro, tal como Nazaré sonhara. E teve enxoval pequeno, mas bonzinho, com as suas peças de seda - cetim lustroso igualmente, renda de loja nas barras. Mariano deu tudo - se ia fazer as coisas, melhor de uma vez fazer bem-feito. (QUEIROZ, 1989, p. 154)

Mariano também construiu uma casinha, mobiliou-a com prazer e zelo. Inicialmente, Nazaré cuidou do lar e da sua enteada com dedicação, mas permanecia o seu principal defeito - o gosto desesperado por rua. la ao teatro, ao cinema, ao circo. Mesmo com o nascimento dos três filhos, continuava a passear pela cidade, bem vestida, esquecendo-se das obrigações maternais. A primeira grande crise do casal deu-se no dia do batizado do José, filho que recebera o mesmo nome do malandro que namorara na mocidade.

Em conversa com sua mãe, sob os protestos dela quanto a essa falta de juízo da filha, Nazaré confessa: "Zezé foi o único homem a quem tive amor neste mundo. Pra mim, no dia em que ele morreu, tudo que prestava se acabou! Por isso me casei com esse molenga ele ou outro, tanto fazia". (QUEIROZ, 1989, p. 177) À distância, Mariano ouviu o diálogo, sem ser pressentido. A confissão da esposa provocou intensa discussão, culminando em agressão física. Mariano, "cego de raiva, de vergonha, de ciúme, ergueu o braço e bateu, bem em cheio, no rosto que amara, que tantas vezes beijara, que talvez ainda continuasse amando. Os nós dos dedos, secos e duros, em cima da boca atrevida, tirando-lhe sangue dos lábios." (QUEIROZ, 1989, p. 177)

Mariano já não mantinha a casa como no início do casamento, nem dava a Nazaré os presentes de que gostava. O trabalho de bicheiro rareava e outros empregos fracassaram. A família pobre aumentava em número de filhos e em demandas para a sua subsistência. Já sabíamos de que Nazaré não se contentava com o mínimo e, com o casamento e o nascimento dos filhos, Nazaré estava mais madura, mais bonita ainda do que quando era mocinha. Na noite da briga, Mariano embebeda-se e dorme na casa da comadre Loura, já viúva. No dia seguinte, passa em casa e encontra os filhos sozinhos. Vê a esposa nas ruas do Rio, usando um vestido claro e curto, os braços de fora, os cabelos soltos pelos ombros, mais parecendo uma mulher jovem e solteira, namoradeira, do que uma mãe de três filhos.

Nazaré ia se fazendo cada vez mais bonita, vestindo cada vez melhor. Apesar das dificuldades financeiras pelas quais passavam, não lhe faltavam vestido, sapato, pintura, frasco de cheiro. Continuava saindo mais e sem pedir licença a ninguém. Um dia, a filha do casal, após apanhar da mãe, conta a Mariano que Nazaré está saindo de barco com um homem. Os dois discutem novamente e a esposa afirma que mantinha o relacionamento extraconjugal há meses: 


\section{Criação \&}

Ele mora do lado de lá, em Ramos, e vem aqui só me ver! Vem à força de remo, porque não é nenhum aleijado, tem dois braços para remar! Vive me pedindo pra ir embora com ele - pois eu vou! Vou ter roupa, vou ter sapato, vou sair, vou ao cinema, vou tomar sorvete em confeitaria chique, na cidade. Vou gozar tudo que você me prometeu e me enganou, seu miséria! Aleijado sem préstimo! Pensava que eu ia viver aqui todo o tempo, feito negra de cozinha, servindo só pra sua escrava? (QUEIROZ, 1989, p. 199).

Mariano foi humilhado duplamente. Primeiro, porque estava sendo traído pela esposa há meses. Segundo, porque Nazaré ressalta o seu defeito físico, decorrente do acidente que sofrera quando Percília morrera. Enfrentado sem qualquer temor, o marido arma-se de facão e vai até a praia, à espera do homem que aviltava o seu lar. Frustrado nessa busca de vingança, Mariano senta-se à sombra de uma amendoeira velha e chora ato comum para esse masculino que vive em marcha à ré. Depois do pranto, retorna a casa, encontrando os filhos sozinhos novamente, os quais lhe informam que Nazaré havia abandonado o lar, conforme prometera. Nesse mesmo dia, Mariano acerta com a comadre Loura a união das duas famílias, ele com quatro filhos e ela com três.

O romance termina com um resumo da trajetória dessa desarrumada família brasileira, constituindo novas mulheres e prenunciando outras transgressões femininas. Mariano ganhando cada vez menos e bebendo cada vez mais, para esquecer as dificuldades financeiras. Dona Loura, envelhecida e fraca, lavando e engomando junto com a filha muda, para ajudar com as despesas da grande família. Gina vivia de cabeça virada, cheia de namoro com um fuzileiro, contra a vontade do pai. A Mundica, fazendo teste para cantora de rádio, profissão considerada inadequada para moças de família, naquela época; a muda Lu entregando-se a qualquer homem:

A natureza é mais forte que o pior castigo, explicava a mãe, envergonhada. A pobrezinha não pratica por maldade; sabe lá o que presta e o que não presta! Pra ela, é como comer e dormir. Faz tudo o que o corpo pede, não entende de mal nem de bem, não tem boca nem ouvido por onde the entre o ensino e o temor de Deus. (QUEIROZ, 1989, p. 214)

Interessante que o narrador não nos informa como se desenvolvia o José, único descendente homem dessas vidas de infortúnios, talvez seguindo o mesmo destino de Mariano, ou de todos os homens, inevitavelmente atendendo aos apelos do feminino, conforme Rachel de Queiroz prenuncia ao abrir esse romance. Por outro lado, podemos também apontar um gesto de desconstrução, como discute Eduardo de Assis Duarte (2003), ao afirmar que o feminismo propõe a revisão de papéis tradicionalmente atribuídos a homens e mulheres, abalando a moral patriarcal e apresentando demandas que pavimentam 0 caminho da desconstrução. Galo de ouro narra essa luta da mulher contra a segregação do 


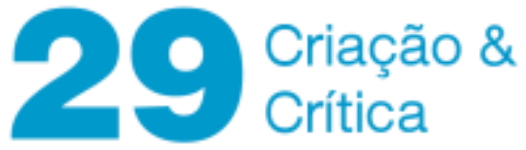

corpo e a busca de uma nova moral sexual que respeite a diferença, como é o caso das mulheres mestiças e pobres ali representadas.

\section{É ele ou eu!}

Último romance de Rachel de Queiroz, publicado em 1992, Memorial de Maria Moura garantiu-Ihe a premiação, em 1993, com o Troféu Juca Pato, distribuído a intelectuais brasileiros pela União Brasileira de Escritores. Essa premiação pode ter sido a motivação para que o crítico mineiro Fábio Lucas escrevesse o ensaio "Aspectos literoculturais da obra de Rachel de Queiroz", no qual ressalta que, depois de 1930, "a carreira literária de Rachel de Queiroz somente conheceu êxitos e novos experimentos." (LUCAS, 2005, p. 57). O autor ressalta, sobretudo, o talento da escritora cearense para 0 gênero crônica. Em seguida, Fábio Lucas afirma que encontrou no Memorial de Maria Moura o momento mais alto da narrativa dessa escritora. Segundo ele, Rachel de Queiroz não se acomodou ao silêncio nem à repetição, de forma que o último romance apresenta a musculatura de um romance complexo.

De fato, o Memorial apresenta renovação técnica na construção narrativa, pois os narradores alternam-se entre as principais personagens que constituem o núcleo da intriga romanesca. O padre (Beato Romano ou padre José Maria) abre o romance, em flash-back, informando-nos da sua chegada à casa forte, onde ficará refugiado sob a proteção da então Maria Moura. Rachel coloca-o como narrador de 11 capítulos; Maria Moura narra o segundo capítulo, vasculhando suas lembranças, a fim de descobrir quem é a estranha personagem que acabara de chegar às suas terras, e é a voz que narra 21 capítulos; o Tonho e o Irineu, primos da Moura, narram 4 capítulos (3 para aquele e 1 para este); Marialva, também prima da Moura, narra 6 capítulos.

Se a técnica narrativa muda significativamente nesse último romance, Rachel não alterou a sua escrita concisa, enxuta e objetiva, já prenunciada desde $O$ quinze, quando sua forma de expressão literária fora confundida por escritores da época como "maneira de escrever masculina". Todos os capítulos são curtos, alguns com pouco mais de uma página apenas. E o mais longo, e talvez o mais significativo para que o leitor compreenda a saga da Moura, é o quarto capítulo, com 28 páginas, no qual a protagonista, depois de receber 0 padre foragido em sua casa forte, rememora a casa materna, a morte do pai, o assassinato da mãe pelo próprio padastro, quem lhe seduz e desonra.

É a partir dessa casa materna que a trama se desenvolverá, dando reforço e sustentação à personalidade ambígua de Maria Moura, ao mesmo tempo destemida, forte e resistente às lutas e conquistas, e fragilizada diante dos apelos inevitáveis do corpo feminino. A meu ver, esse caráter ambíguo da personagem quanto ao desejo de independência da mulher e sua susceptibilidade à vontade de prazer com um homem constitui uma chave de leitura para os romances da escritora cearense. Suas narrativas demonstram que a mulher 


\section{Criaçãa \&}

não pode ser feliz nem se sentir realizada socialmente sem a companhia de um homem, ainda que quase todas as protagonistas femininas procurem não se submeter às vontades masculinas nem se conformarem ao espaço doméstico.

Para discussão desse caráter ambíguo de Maria Moura, partimos, portanto, do quarto capítulo, no qual a personagem rememora como iniciou a sua saga de banditismo e as suas transformações físicas e morais. Quando ela procurou o padre José Maria para fazer a confissão de que havia se entregado a Liberato, o homem que vivia amasiado com a sua mãe, a protagonista tinha 17 anos e ainda acreditava no poder redentor da religião. Naquele tempo, os trabalhadores de sua casa a tratavam de Sinhazinha, era uma moça simples e delicada, até que Liberato influencia a sua completa transformação, começando pela sua liberação sexual:

No meio da noite eu escutava o Liberato chegando da vila, as esporas tinindo no ladrilho. Ele via a réstia de luz da candeia, acesa no meu quarto, às vezes com o pavio quase apagando. (...) Bem, a noite escura é traidora. Como é que Mãe dizia para afastar a tentação? "Valha-me a Virgem Puríssima!" Mas a Virgem Puríssima não me valeu.

Afinal, ele era um homem bonito; devia ser mais novo do que Mãe. Pelo menos parecia, e era o que dizia todo mundo.

Sempre no escuro, nunca de dia - isso era ele. Ah, bem se diz, carinho não dói. $E$ talvez, desde menina, no fundo do coração, eu tivesse inveja de Mãe: aquele homem enxuto de corpo, branco de cara, cabelo crespo, mostrando os dentes sem falha quando se ria.

Começou mais como brincadeira. E aos poucos, bem aos poucos, é que foi ficando uma brincadeira perigosa.

Devagar, devagar. Os carinhos se tornando cada noite mais atrevidos, se adiantando, indo longe demais. (QUEIROZ, 1992, p. 20)

Sabemos que Liberato assassinara a mãe de Maria Moura objetivando tomar-lhe as terras da fazenda Limoeiro. Depois de seduzir a adolescente, o padrasto investe em uma campanha sobre ela para que assine uma procuração, outorgando-lhe poder de negócio em relação à propriedade. Vendo-se forçada, sob ameaças veladas de morte, Maria Moura arquiteta um plano para matar Liberato, usando seu poder de sedução sobre Jardilino, um mulato empregado da fazenda, conduzindo-o ao crime: " $E$ eu não tinha mais nada da mocinha boba do tempo de Mãe. Sabia muito bem o que um homem quer da gente - mesmo sendo um caboclo como o Jardilino." (QUEIROZ, 1992, p. 25)

Maria Moura seduz o mulato e finge estar apaixonada por ele, pronta a casar-se, desde que Liberato saia do seu caminho. Para conseguir seu intento, arma o enamorado de espingarda e planeja uma emboscada na qual se mate o seu padrasto. Assim que 0 plano é executado, a teia da aranha se estende ao próprio Jardilino, pois a Moura não se 


\section{Criaçäo \&}

casaria com ele, nem permitiria que fosse acusada de mandante do crime. Então, João Rufo, trabalhador da fazenda e amigo da família, será o homem manipulado ardilosamente para limpar as pistas e desobstruir o caminho de transição da sinhazinha em direção à guerreira masculinizada.

O último ritual dessa transformação se dá com a investida dos primos Tonho e Irineu, na tentativa de tomar-Ihe as terras ou de casar Maria Moura com Irineu. Para esse fim, os irmãos tomam de assalto armado a fazenda da prima. Ela ateia fogo a casa e foge, já sabedora das terras dos padres, em lugar distante, que o avô do seu pai comprara e ninguém ainda havia tomado posse. É para lá que ela se dirige, junto com João Rufo e outros poucos companheiros, em busca de um tesouro escondido e procurando refazer sua vida:

Vou prevenir a vocês: comigo é capaz de ser pior do que com cabo e sargento. Têm que me obedecer de olhos fechados. Têm que se esquecer de que eu sou mulher - pra isso mesmo estou usando estas calças de homem.

Bati no peito:

_ Aqui não tem mulher nenhuma, tem só o chefe de vocês. Se eu disser que atire, vocês atiram; se eu disser que morra é pra morrer. Quem desobedecer paga caro. Tão caro e tão depressa que não vão ter tempo nem para se arrepender. (...) puxei o meu cabelo que descia pelas costas feito numa trança grossa; encostei o lado cego da faca na minha nuca e, de mecha em mecha, fui cortando o cabelo na altura do pescoço. (...)

_ Agora se acabou a Sinhazinha do Limoeiro. Quem está aqui é a Maria Moura, chefe de vocês, herdeira de uma data na sesmaria da Fidalga Brites, na Serra dos Padres. (QUEIROZ, 1992, p. 84)

Nesse trânsito de identidades e de espaços, Maria Moura se esforça para assumir uma fisionomia e um comportamento rústico, endurecido, já que o seu desejo era de vingança contra os primos que the expulsaram de sua propriedade. Ela agora queria ter força, queria ter fama, queria apagar qualquer lembrança da menina mimada que recebia os cuidados de todos na fazenda Limoeiro, quando a mãe ainda era viva. Em suas reflexões, Maria Moura declara a sua sede de poder, de riquezas, de ser reconhecida como gente, e gente grande, influente.

Ainda que esse projeto se cumpra parcialmente, Maria Moura não consegue dominar os seus impulsos femininos, manifestados desde os pequenos gestos, como adornos de joias até a vontade de ser possuída por um homem: "Eu sonhava com um homem - não sei que homem eu queria, mas sabia que tinha que ser um homem. Algum dia." (QUEIROZ, 1992, p. 122). Em outra passagem do romance, fragilizada pela doença, Maria Moura se angustia pela solidão e, em solilóquio, comenta: "Acho que não nasci para essa vida que arrumei pra mim. Sozinha, sem um homem, sim, falando franco, sem um homem. Toda 


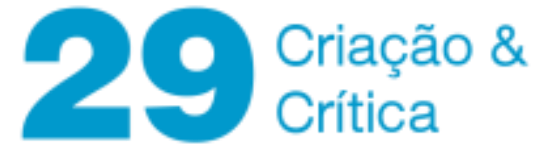

mulher quer ter um homem seu (...) Mão de homem, braço de homem, corpo de homem." (QUEIROZ, 1992, p. 201).

Essa cena é significativa porque vem entrecortada de contradições. É quase inacreditável que até o repulsivo Irineu, seu primo, durante uma luta corporal tentando novamente capturá-la, tenha lhe despertado sensações eróticas agradáveis, desejo de prazer. Ao mesmo tempo em que a Moura afirma sua dependência a um homem viril, que lhe fizesse sentir-se mulher, dominada, possuída, afirma que gosta de ser senhora dos homens, de comandá-los. Em suas palavras:

Me sinto bem, montada na minha sela, do alto do meu cavalo, rodeada dos meus cabras; meu coração parece que cresce, dentro do meu peito. Mas, por outro lado, também queria ter um homem me exigindo, me seguindo com um olho cobiçoso, com ciúme de mim, como seu fosse coisa dele. (QUEIROZ, 1992, p. 202)

Maria Moura recorta sua aparente feminilidade e forja uma identidade masculinizada, mas não consegue reprimir seus desejos heterossexuais e, em alguns momentos, sua vontade de apresentar-se como uma mulher comum, cuidando de suas roupas, de seus adornos, de sua casa, e de ver-se acompanhada de um homem forte, viril, que a fizesse mulher de verdade. Em outra passagem, Maria Moura lamenta que, se o seu pai não tivesse morrido, talvez agora estivesse casada, dormindo nos braços do seu marido. Essas reflexões aparecem em muitos capítulos narrados pela moça guerreira.

Maria Osana de Medeiros Costa, em "Maria Moura, uma saga de poder, amor e morte", também discute essa construção de uma identidade masculinizada para a protagonista, mas a partir do espelhamento na história de crimes e de pecados da carne cometidos pelo padre José, ou Beato Romano. Sua análise é interessante porque aproxima, por meio dos estudos de gênero, essas duas personagens. Segundo essa autora, a história dos três crimes decorrentes do relacionamento amoroso com Dona Bela estabelece uma curiosa relação com a história também dos três crimes premeditados por Maria Moura:

Maria Moura e o Beato Romano são vozes que se complementam e, curiosamente, fora do universo familiar. Os elos que os unem são um segredo de confissão e uma cumplicidade de crimes e amores proibidos, que sinalizam para uma "análise da construção do gênero e da sexualidade' onde 'o que fora iniciado com o feminino passa a contemplar também o masculino". (COSTA, 2002, p. 184)

Instalada nas terras que eram do seu bisavô, olhando a casa forte ali construída e as benfeitorias realizadas na fazenda, além do gado que agora criava, a Moura se orgulhava das conquistas e do seu poder, que era conhecido em terras distantes. Nada disso, no 


\section{Criacăo \&}

entanto, supria a falta de um homem. Até que chega à casa forte um seu primo bastardo, o Duarte que, à primeira vista, Ihe seduz: "Olhei pra ele. Cada vez me agradava mais, até mesmo como homem. Nunca tinha andado perto de mim nenhum rapaz como aquele - na força do homem, bonito de cara -, alto, forte, calmo, bom de riso." (QUEIROZ, 1992, p. 299)

Com Duarte, Maria Moura viveu bons e agradáveis momentos. O rapaz era obediente e servil, durante o dia e, à noite, era o homem viril admirado por ela, desejosa de tê-lo sempre ao seu lado, ainda que os companheiros de luta desconhecessem esse relacionamento afetivo da chefe. Durante esse tempo, Maria Moura apazigua o seu conflito interior, pois conseguiu apresentar-se masculinizada e durona durante o dia, e femininizada e sensível durante a noite. Com Duarte, a Moura pôde conciliar a sua dupla personalidade. Mas o rapaz precisou afastar-se a trabalho, quando chega à casa forte um jovem louro, bonito, sob encomenda de proteção e de cuidados da Moura, pois havia se envolvido em uma briga por posses de terras e estava sendo perseguido pela família de um homem morto nesse confronto.

Em pouco tempo, o jovem Cirino despertará o interesse sexual da sua protetora e se apossará de Maria Moura com violência, mas sem a sua resistência. A força do sangue imperou sobre ela, que não conseguia mais viver sem o seu protegido:

Com o passar dos dias, já não era só à noite que eu procurava a companhia dele. (...) Meu corpo chegava a doer quando a gente se tocava - e continuava doendo quando se separava. Assim mesmo eu procurava disfarçar de todo mundo as fraquezas da Moura nova, fingindo a antiga dureza, a da Moura de antes. (QUEIROZ, 1992, p. 393).

Maria Moura percebe o perigo desse poder que um homem como Cirino exerce sobre ela. Então, vendo-se à beira do precipício, pensando mesmo em entregar-lhe a casa, a fazenda, os homens, o comando de tudo para ser apenas sua mulher, resolve matá-lo: "Agora era ele, ou eu", sentencia a Moura. Para esse fim, promete a Valentin, marido de sua prima Marialva, os quais viviam em sua propriedade, que deixaria tudo o que tinha como herança para o filho deles, se Cirino morresse. A ardilosa aranha, mais uma vez, estendeu os seus fios e armou a sua rede, conduzindo Valentin ao assassínio para que ela pudesse ver-se livre do amante que ameaçava a sua independência afetiva.

O romance termina com a ordem dos sentimentos reestabelecida e a Moura a caminho de mais uma batalha, contra soldados que vêm em sua captura. Fábio Lucas interpreta com muita argúcia essa cena, a partir da acentuação de um traço dominante na personalidade de Maria Moura: o da aventura,

em primeiro plano, de que deriva o gosto da viagem e da luta, numa demonstração cabal de nomadismo. Tem a têmpera de um herói de romance 


\section{Criação \&}

de cavalaria. Não é o pouso da casa, agarrada ao lombo da serra, que traduz o seu ideal. Antes é o apelo da estrada que a seduz, o desafio para a conquista de novas posses, segundo o princípio da força e da violência, sob a regência da cobiça. (LUCAS, 2005, p. 66-67)

Esse final talvez signifique a morte simbólica de uma dupla personalidade. Rachel poderia, mais uma vez, como o fizera em $O$ quinze, alertar às mulheres que é impossível seguir um feminismo radical. Uma mulher não pode assumir uma identidade masculina nem se tornar um homem ou agir completamente como os homens agem. Uma mulher não pode, segundo a ficção produzida por Rachel de Queiroz, existir sem a companhia de um homem forte, viril, que faça uma mulher se sentir fêmea, de verdade. Em um sentido ou em outro, o romance não finaliza com essa cena, pois não se fecha na imaginação do leitor, o qual fica na expectativa de uma nova aventura, como se lhe faltasse o último capítulo.

\section{Referências bibliográficas}

CARONE, Modesto. Resumo de Ana. São Paulo: Companhia das Letras, 1998.

COSTA, Maria Osana de Medeiros. "Maria Moura, uma saga de poder, amor e morte." In: DUARTE, Constância Lima; DUARTE, Eduardo de Assis; BEZERRA, Kátia da Costa (orgs). Gênero e representação na Literatura Brasileira. Belo Horizonte: Editora da UFMG, 2002. p. 183-189.

DUARTE, Eduardo de Assis. "Classe e gênero no romance de Rachel de Queiroz". In:

Literatura, política, identidades - ensaios. Belo Horizonte: Editora da UFMG, 2005.

DUARTE, Eduardo de Assis. "Feminismo e desconstrução: anotações para um possível percurso". In: BRANDÃO, Izabel; MUZART, Zahidé L. Refazendo nós. Florianópolis: Editora Mulheres, 2003.

HOLLANDA, Heloísa Buarque de. "O éthos Rachel". In: Cadernos de Literatura Brasileira. Número 4. São Paulo: Instituto Moreira Salles, 1997.

LUCAS, Fábio. "Aspectos literoculturais da obra de Rachel de Queiroz". In: Lições de Literatura Nordestina. Salvador: Fundação Casa de Jorge Amado, 2005. p. 55-66.

OLIVA, Osmar Pereira. "Rachel de Queiroz e o romance de 30: ressonâncias socialistas e feministas". In: Cadernos Pagu, no 43, Campinas Jul/Dez. 2014, disponível em http://www.scielo.br/scielo.php?script=sci_arttext\&pid=S0104-83332014000200385, acesso em 28 de março de 2020.

QUEIROZ, Rachel de. O galo de ouro. In: Obra reunida. v. 3. Rio de Janeiro: Editora José Olympio, 1989.

QUEIROZ, Rachel de. Memorial de Maria Moura. São Paulo: Siciliano, 1992. 


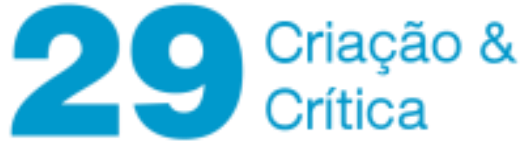

QUEIROZ, Rachel de. Cadernos de Literatura Brasileira. Número 4. São Paulo: Instituto Moreira Salles, 1997.

Recebido em: 28/03/2020 Aceito em: 08/05/2020

Referência eletrônica: OLIVA, Osmar Pereira. Galo de Ouro e Memorial de Maria Moura: Rachel de Queiroz e as contradições do feminino - entre a independência e a conformação. Criação \& Crítica, n. 29, p., mai. 2021. Disponível em: <http://revistas.usp.br/criacaoecritica>. Acesso em: dd mmm. aaaa. 